\title{
Análise numérica de vigas de aço em incêndio com dilatação térmica restringida
}

\author{
Julia Souza Nascimento ${ }^{1 *}$; Macksuel Soares de Azevedo²; Valdir Pignatta e \\ Silva $^{3}$; Walnório Graça Ferreira ${ }^{2}$ \\ ${ }^{1}$ Mestranda em Engenharia, Universidade Federal do Espírito Santo, \\ jsnascimento.es@gmail.com \\ 2 Professor do Departamento de Engenharia Civil, Universidade Federal do \\ Espírito Santo, macksuel.azevedo@gmail.com \\ ${ }^{3}$ Prof. Doutor, Departamento de Engenharia de Estruturas da Escola \\ Politécnica, Universidade de São Paulo, valpigss@usp.br
}

\section{Behavior of axially restrained beam subjected to fire}

\begin{abstract}
Resumo
Vigas de aço tendem a expandir longitudinalmente quando submetidas a temperaturas elevadas. Em situações reais, esse deslocamento axial é impedido por estruturas adjacentes que ainda podem aplicar restrição à rotação de acordo com o tipo de ligação existente. Essa interação entre os elementos favorece o surgimento de esforços internos que influenciam o comportamento da viga, a qual já apresenta capacidade resistente reduzida em resposta à degradação térmica de suas propriedades físicas e mecânicas. O objetivo desta pesquisa é simular numericamente o comportamento de vigas de aço com restrições axial e rotacional nos apoios em situação de incêndio. A análise numérica foi realizada no código computacional ANSYS v17.0, considerando-se as não linearidades geométricas e do material.
\end{abstract}

Palavras-chave: Incêndio. Aço. Vigas. Restrição axial. Restrição rotacional.

\begin{abstract}
Steel beams tend to elongate under fire conditions. In real structures, this behavior is axially restrained by the adjacent parts of the whole frame which can also impose rotational restraint according to the type of connection between them. These restraints induce significant forces in the beam, which already has the resistance reduced due to thermal degradation of its mechanical and physical properties. The focus of this paper is a numerical validation of a steel beam with axial e rotational restraints under fire conditions. A finite element model was created using ANSYS v17.0, including both material and geometrical nonlinearities.
\end{abstract}

Keywords: Fire. Steel. Beams. Axial restraint. Rotational restraint. 


\section{Introdução}

Vigas de aço em situação de incêndio têm sua capacidade resistente reduzida em razão da degradação térmica de suas propriedades físicas e mecânicas. A ABNT NBR 14323:2013 apresenta o dimensionamento dessas vigas sem considerar a influência da estrutura em que elas estão inseridas que, por sua vez, impede deslocamentos e restringe a rotação de acordo com o tipo de ligação existente. Essa interação favorece o surgimento de esforços internos que tornam o comportamento da viga restringida diferente daquele apresentado pelo elemento isolado. Sabendo disso, alguns autores avaliaram tanto experimentalmente como numericamente vigas submetidas a temperaturas elevadas.

Liu et al. (2002) estudaram os efeitos das ligações e das restrições axiais em vigas submetidas ao aquecimento segundo a curva de incêndio-padrão ISO 834:1999 em um experimento realizado na Universidade de Manchester. Li e Guo (2008) realizaram um ensaio semelhante, no entanto, considerando um incêndio natural por meio de uma curva temperatura-tempo arbitrária que incluía a fase de aquecimento e resfriamento. Ambos os autores notaram a presença de uma força de compressão induzida que, combinada com o momento fletor negativo devido à ligação semirrígida nas extremidades, provocaram instabilidades locais na mesa inferior.

Yin e Wang (2004) fizeram uma análise paramétrica que investigou a influência do comprimento do vão, do nível de carregamento, das restrições axiais e rotacionais isoladamente e da instabilidade lateral com torção em vigas com distribuição de temperatura uniforme e não uniforme na seção transversal. Concluiu-se que a presença da força de restrição proporcionou à viga maior resistência ao fogo em relação a viga simplesmente apoiada, uma vez que a temperaturas elevadas ocorre a inversão do esforço de compressão para tração e a redução do momento fletor positivo (Moss et al., 2004; Kucz et al., 2013). Além disso, observaram que, quanto maior a rigidez axial, menor é a flecha, o que é favorável a integridade do compartimento no qual a viga se encontrar. Tan e Huang (2005), Li et al. (2007) e Dwaikat e Kodur (2011) foram outros autores que analisaram numericamente o comportamento dessas vigas e escolheram arbitrariamente uma distribuição de temperatura linear e não uniforme. 
No Brasil, poucos pesquisadores trataram desse assunto. Silva (1997) e Mourão (2004) avaliaram vigas de aço em situação de incêndio admitindo que as restrições axiais e rotacionais possuíssem rigidez infinita, o que é uma situação idealizada que não ocorre na prática, além de considerar um aquecimento uniforme da seção transversal. Nesse contexto, o presente artigo tem por objetivo simular numericamente o experimento realizado por Liu et al. (2002) a fim de criar um modelo numérico que servirá de base para novas pesquisas relacionadas ao tema, considerando níveis de restrições axial e rotacional e a curva de incêndio-padrão ISO 834.

\section{Modelo experimental de referência}

Liu et al. (2002) estudaram os efeitos da restrição axial e rotacional de vigas em situação de incêndio. Para isso, foi realizada uma série de ensaios em um novo forno à época construído na Universidade de Manchester, no qual vigas sem revestimento contra fogo foram submetidas a carregamento constituído por duas forças concentradas, como mostra a Figura 2.1.

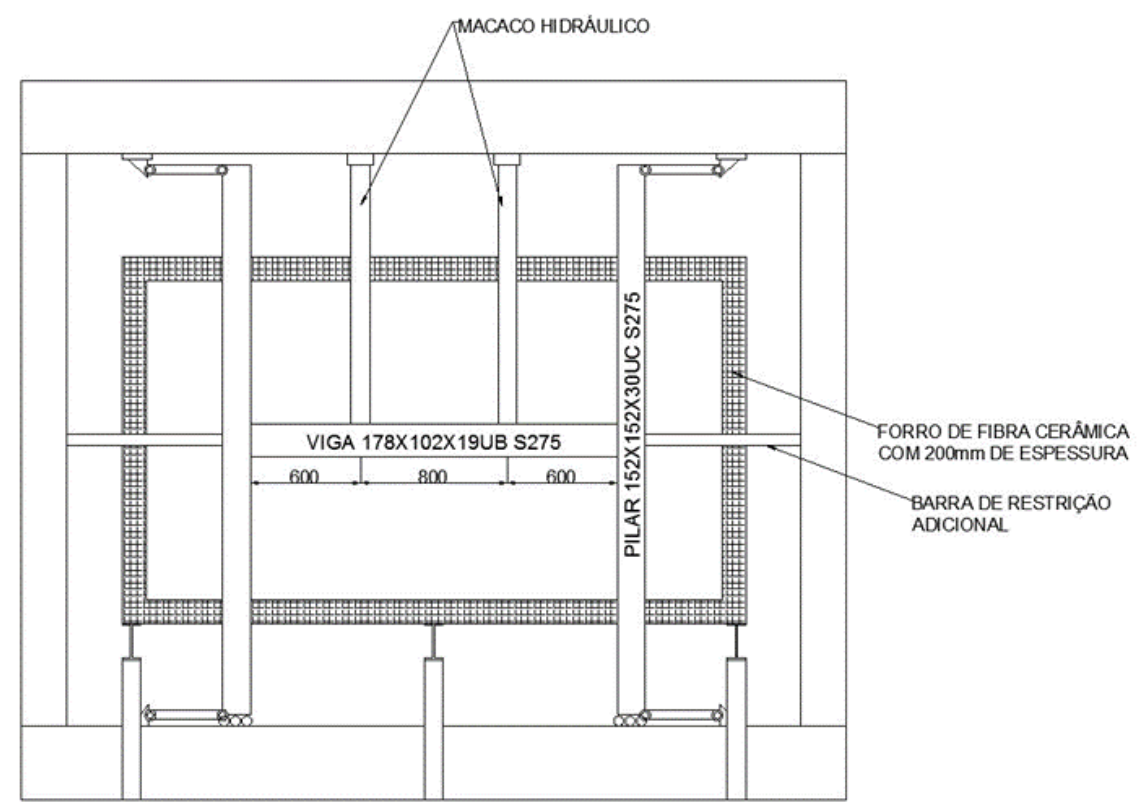

Figura 2.1 - Estrutura de ensaio (Liu et al., 2002, adaptado) 
O aquecimento da viga, de seção 178x102x19 UB (S275), foi feito segundo a curva de incêndio padrão ISO 834. A fim de simular a presença da laje de concreto na mesa superior do perfil, que não está diretamente exposta ao incêndio, foi colocada uma manta cerâmica de 15 mm de espessura. Os pilares, de seção 152×152x30 UC (S275), e as ligações também foram revestidos com o mesmo material, porém com $50 \mathrm{~mm}$ de espessura. As forças transversais foram aplicadas por dois macacos hidráulicos independentes posicionados a $600 \mathrm{~mm}$ das extremidades da viga.

Dois tipos de ligações foram utilizados: com placa de extremidade e dupla cantoneira de alma. Essa última, por se tratar de uma ligação flexível e não transmitir momento significativo, foi dimensionada apenas ao esforço cortante. As cantoneiras eram de seção $75 \times 75 \times 8$ e ligadas por parafusos M16 classe 8.8. A placa de extremidade possuía $10 \mathrm{~mm}$ de espessura e também era ligada por parafusos M16 classe 8.8. A Figura 2.2 mostra os dois tipos de ligação considerados.

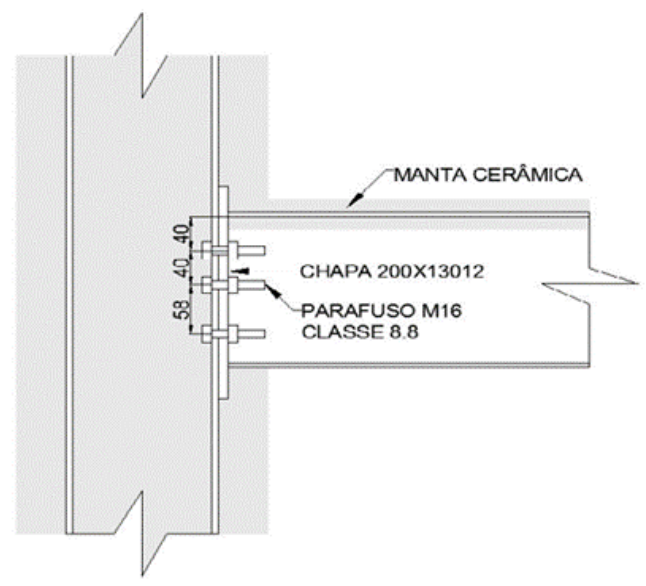

a) Ligação com placa de extremidade

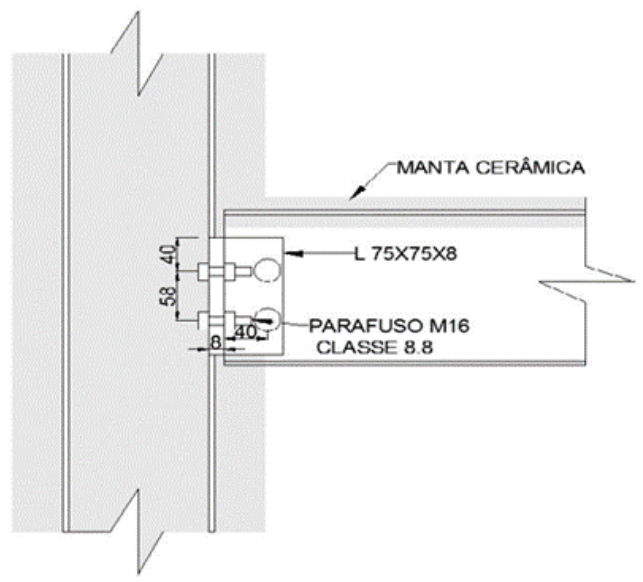

b) Ligação com dupla cantoneira

Figura 2.2 - Tipos de ligação (Liu et al., 2002, adaptado)

O plano de ensaio consistiu na realização de experimentos com três níveis de carregamento diferentes, equivalentes a 30\%, 50\% e $70 \%$ do momento fletor resistente de uma viga biapoiada à temperatura ambiente. O carregamento era aplicado manualmente, à temperatura ambiente, e mantido constante durante o ensaio. As 
restrições axiais foram impostas pelo pilar 152x152x30UC (S275), no valor de $8 \mathrm{kN} / \mathrm{mm}$, e pela barra (restrição externa), no valor de $35 \mathrm{kN} / \mathrm{mm}$ ou $62 \mathrm{kN} / \mathrm{mm}$.

Os primeiros ensaios foram realizados em vigas com ligação de placas de extremidade. Notou-se que as vigas falhavam prematuramente por instabilidade local da alma entre a ligação e ponto de aplicação de força. Como esse tipo de falha não era previsto no experimento, enrijecedores horizontais foram soldados à meia altura da alma da viga, como mostra a Figura 2.3. Na simulação numérica, a espessura do enrijecedor horizontal foi admitida igual à espessura das mesas uma vez que maiores informações não foram fornecidas por Liu et al. (2002).

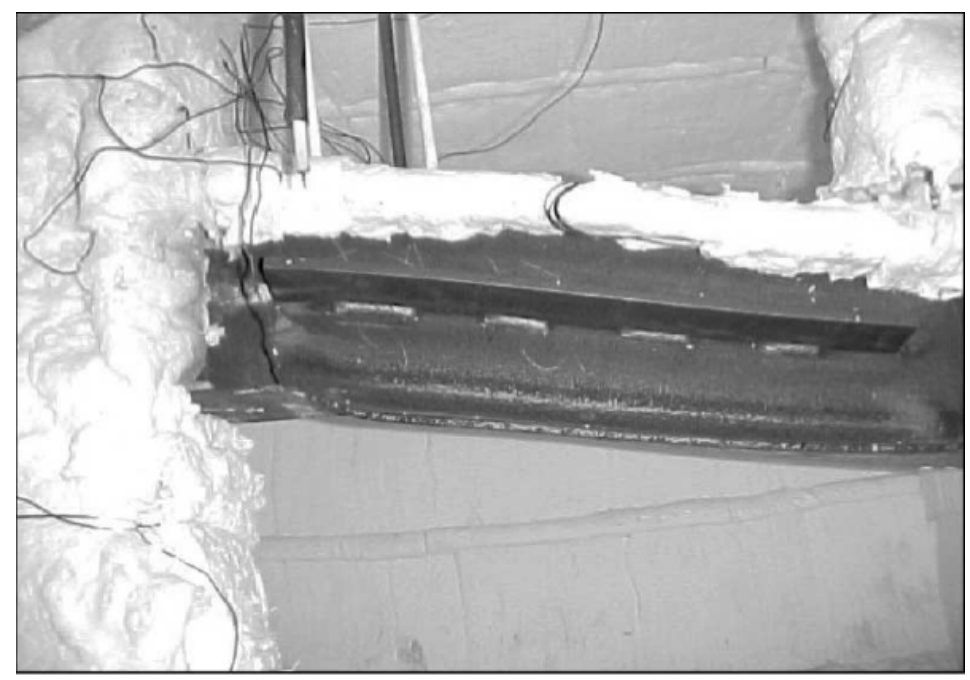

Figura 2.3 - Enrijecedor horizontal soldado na viga (Liu et al., 2002)

\section{Análise numérica}

A análise numérica desenvolvida nesse artigo utilizou rotinas de programação denominadas APDL (Ansys Parametric Development Language) do programa de computador ANSYS 17.0. Os modelos elaborados foram estudados em três etapas: análise térmica transiente, análise estática não linear à temperatura ambiente e análise termestrutural. Os procedimentos adotados na análise térmica foram os mesmos já utilizados em Regobello (2007), Kimura (2009) e Dorr (2010). Em razão dos bons resultados obtidos em Dorr (2010), optou-se pelo uso do elemento finito SHELL 131 para modelar a viga de aço e do elemento finito SURF 152 para aplicar os efeitos térmicos. 
O elemento SHELL 131 possui quatro nós e informa o campo de temperatura através do plano e da seção transversal. Esse elemento é tridimensional do tipo casca, pode ser decomposto em camadas, possui até 32 graus de liberdade relacionados à temperatura e é utilizado tanto em análises térmicas estacionárias quanto em análises térmicas transientes. O elemento SURF 152 é definido por quatro a nove nós e é utilizado para representar a transferência de calor do meio para o elemento aquecido por convecção e radiação. A opção do nó extra permite que seja aplicada uma temperatura no ambiente que corresponde a temperatura dos gases na situação de incêndio. Dessa forma, o nó extra funciona como uma fonte de calor.

O campo de temperaturas gerado na análise térmica pode ser transferido para o elemento finito de uma análise estrutural, desde que haja compatibilidade entre os elementos usados nas diferentes análises. No caso do elemento térmico SHELL 131, o elemento estrutural correspondente é o SHELL 181. Este elemento possui quatro nós e seis graus de liberdade em cada um deles: translação nas direções x,y e z, e rotação em torno dos eixos $x, y$ e $z$.

O elemento de mola COMBIN 14 foi utilizado para modelar as restrições axiais e rotacionais. Esse elemento possui capacidade de se deslocar longitudinalmente ou de torção, e pode ser usado em aplicações unidimensionais, bidimensionais ou tridimensionais. Essas restrições foram aplicadas em regiões rígidas criadas nas extremidades das vigas com o elemento MPC 184, que é um elemento finito rígido, com dois nós e que pode ser usado como barra ou viga. Caso o elemento seja de barra, ele possui três graus de liberdade em cada nó: translação nas direções x, y e z. Se o elemento for de viga, ele possui seis graus de liberdade em cada nó: translação nas direções $x, y e$ $z$, e rotação em torno dos eixos $x, y$ e $z$. A Figura 3.1 ilustra o modelo estrutural criado e as condições de contorno nos apoios.

Com o objetivo de melhorar o tempo de processamento computacional, utilizou-se o recurso da simetria (comando DSYM), no qual apenas metade da estrutura é modelada. Devido ao uso desse recurso, a translação em $X$ e as rotações em $Z$ e $Y$ foram impedidas no meio do vão, como ilustra a Figura 3.2. 


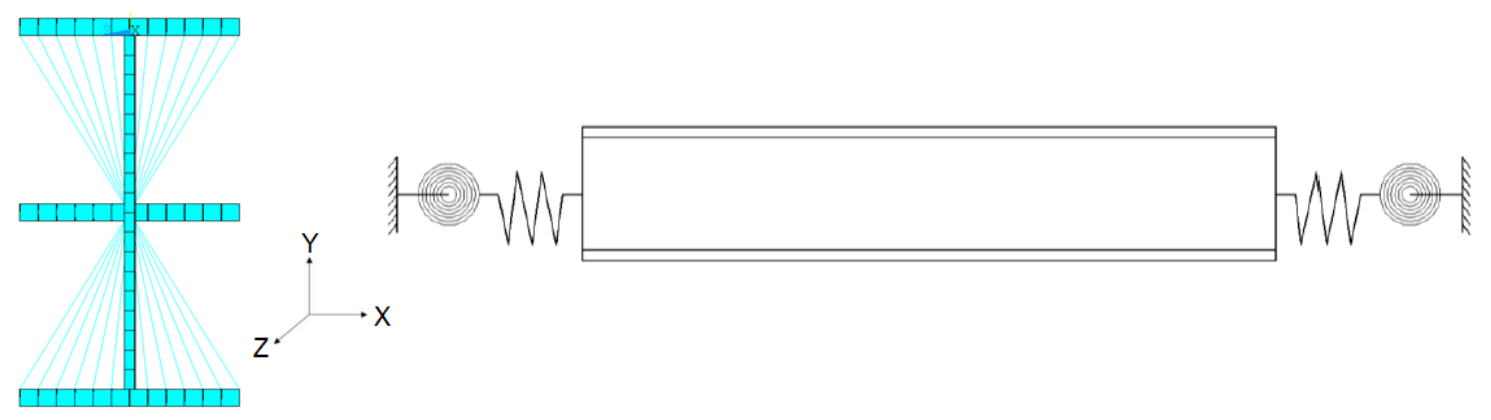

Figura 3.1 - Detalhamento dos apoios e modelo estrutural completo
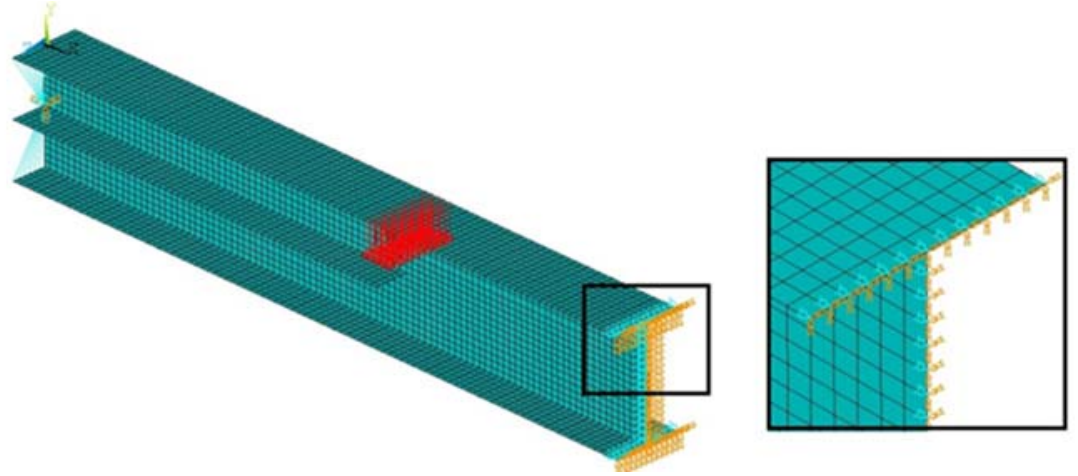

Figura 3.2 - Recurso da simetria na construção do modelo numérico

\section{Validação do modelo numérico}

O modelo numérico foi validado considerando os três níveis de carregamento, $30 \%, 50 \%$ e 70\%, ligação do tipo chapa de extremidade e restrição axial igual a $8 \mathrm{kN} / \mathrm{mm}, 35$ $\mathrm{kN} / \mathrm{mm}$ e $62 \mathrm{kN} / \mathrm{mm}$. Embora os autores não tenham fornecido o valor da restrição rotacional, Yin e Wang (2004) assumiram que esse tipo de ligação tinha uma rigidez rotacional de $14000 \mathrm{kNm} / \mathrm{rad}$. e o mesmo valor foi adotado no modelo. As propriedades térmicas foram determinadas conforme os procedimentos da ABNT NBR 14323:2013. Os valores da resistência ao escoamento e do módulo de elasticidade foram adotados iguais a $275 \mathrm{MPa}$ e $210000 \mathrm{MPa}$, respectivamente. Por se tratar de um experimento europeu, adotou-se o módulo de elasticidade segundo o EUROCODE 3 Part 1.1 (2005). A validação numérica teve início com a criação do modelo térmico. No experimento de Liu et al. (2002), a mesa superior da viga de aço foi revestida com uma manta cerâmica 
a fim de se criar um gradiente de temperatura na seção transversal do perfil. No presente artigo, definiu-se a mesa superior sendo adiabática assim como Hanus (2008), que validou seu trabalho com o mesmo experimento. Segundo esse autor, essa consideração não está de acordo com a realidade uma vez que o revestimento contra fogo impede o fluxo de calor por um período limitado de tempo, no entanto, a precisão obtida é suficiente para fazer com que a distribuição de temperatura seja aceita na análise. Como no ensaio, a análise térmica durou aproximadamente 40 minutos e o aquecimento seguiu a curva de incêndio-padrão ISO 834. A Figura 4.1 ilustra o modelo térmico criado.

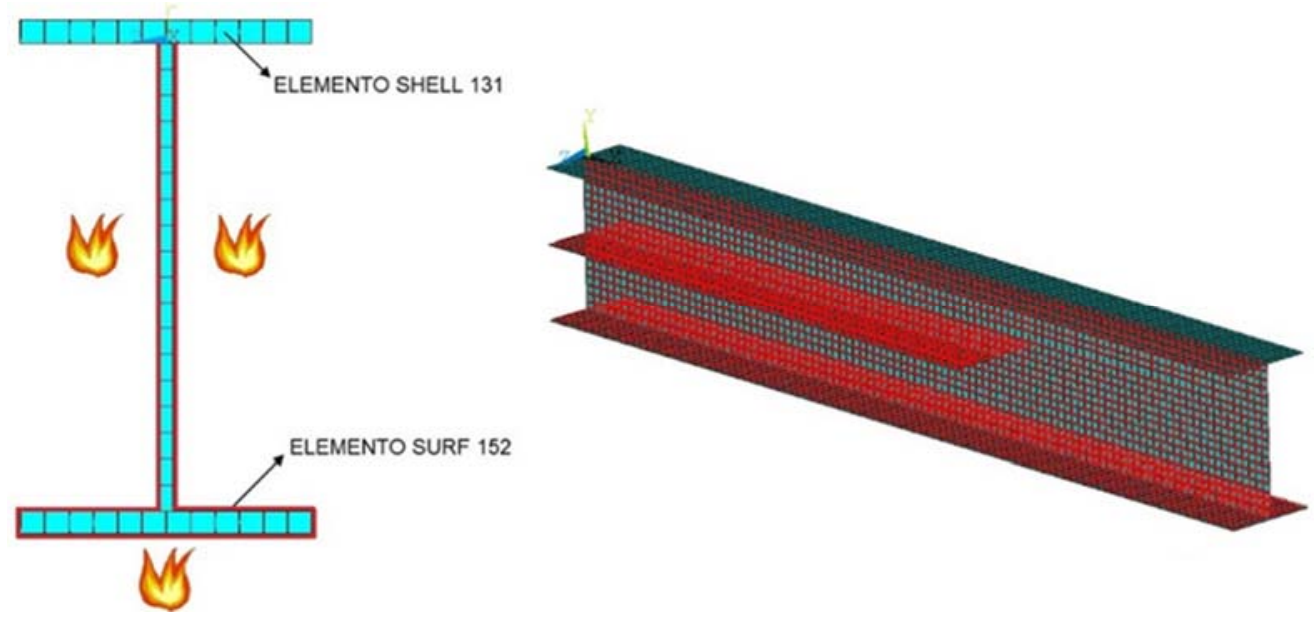

Figura 4.1 - Modelo térmico

O gráfico da Figura 4.2 compara os resultados obtidos numericamente e experimentalmente. Nota-se que, embora a mesa superior tenha sido considerada adiabática, os valores obtidos na análise numérica se aproximam dos valores obtidos no experimento. 


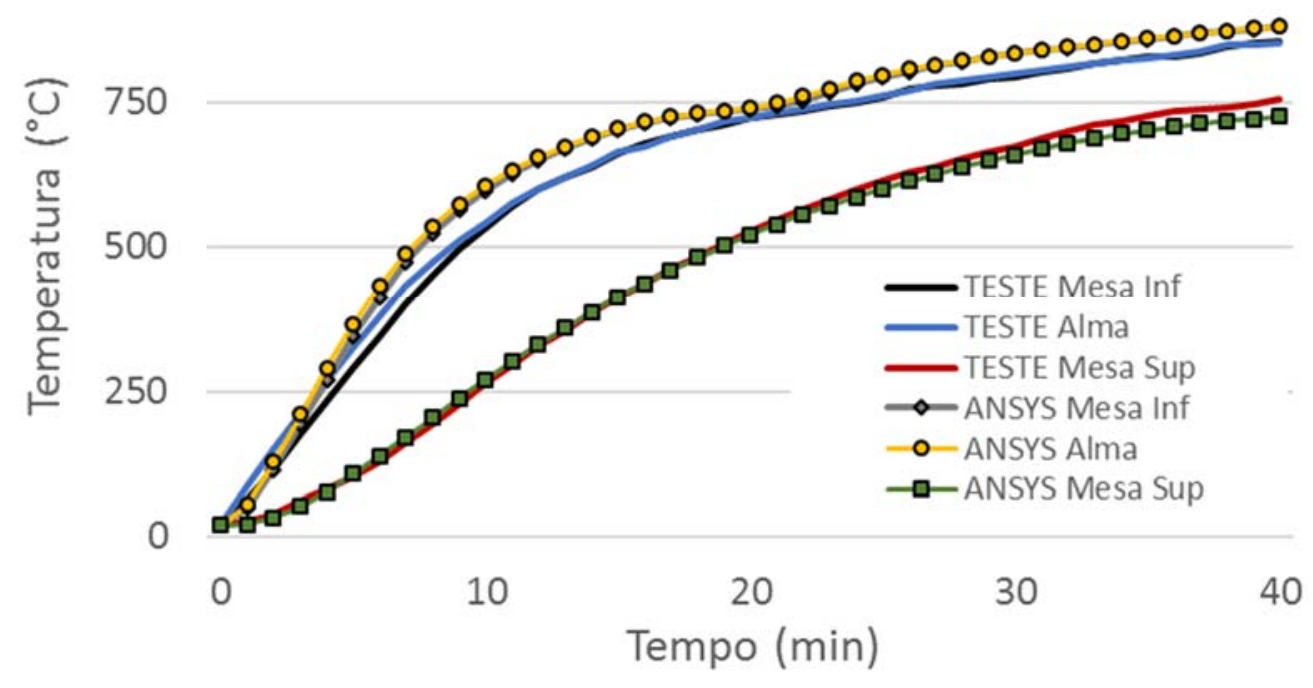

Figura 4.2 - Elevação da temperatura nos modelos experimental e numérico

Após a validação do modelo térmico, a análise estrutural não linear à temperatura ambiente foi executada. Primeiramente, substituiu-se o elemento finito térmico SHELL 131 pelo elemento estrutural equivalente, SHELL 181. Nas extremidades da viga, foram criadas regiões rígidas que tinham o seu comportamento condicionado a um nó mestre localizado a meia altura do perfil. A esse nó mestre, aplicaram-se restrições aos deslocamentos nas direções $Y$ e $Z$ e às rotações em torno dos eixos $X$ e $Y$. As restrições axiais e rotacionais foram modeladas com dois elementos de mola, sendo um deles com grau de liberdade relacionado a translação em $\mathrm{X}$, e o outro com grau de liberdade relacionado a rotação em $Z$.

Após a análise estática, a análise termestrutural foi realizada com o acoplamento dos resultados obtidos na análise térmica. $\mathrm{O}$ campo de temperaturas foi aplicado em cada nó e para cada passo de carregamento, na forma de carregamento de volume (bodyload). As forças aplicadas foram mantidas constantes durante todo o aquecimento. Nessa etapa, os valores da curva multilinear tensão versus deformação e do módulo de elasticidade foram ponderados pelos fatores de redução decorrentes do aumento de temperatura fornecidos pela ABNT NBR 14323:2013. O coeficiente de Poisson foi mantido constante e igual a 0,3 . 
Os resultados da análise termestrutural foram comparados ao experimento de Liu et al. (2002), em termos de força axial de restrição e flecha no meio do vão, para os três níveis de carregamento, obtendo o mesmo nível de aproximação entre os resultados numéricos e experimental. Os valores foram extraídos do nó ao qual se aplicou a mola axial e do nó posicionado no meio do vão, a meia altura da alma. A temperatura de referência no eixo das abscissas foi obtida da mesa inferior. Na Figura 4.3, vê-se a comparação do nível 70\%.
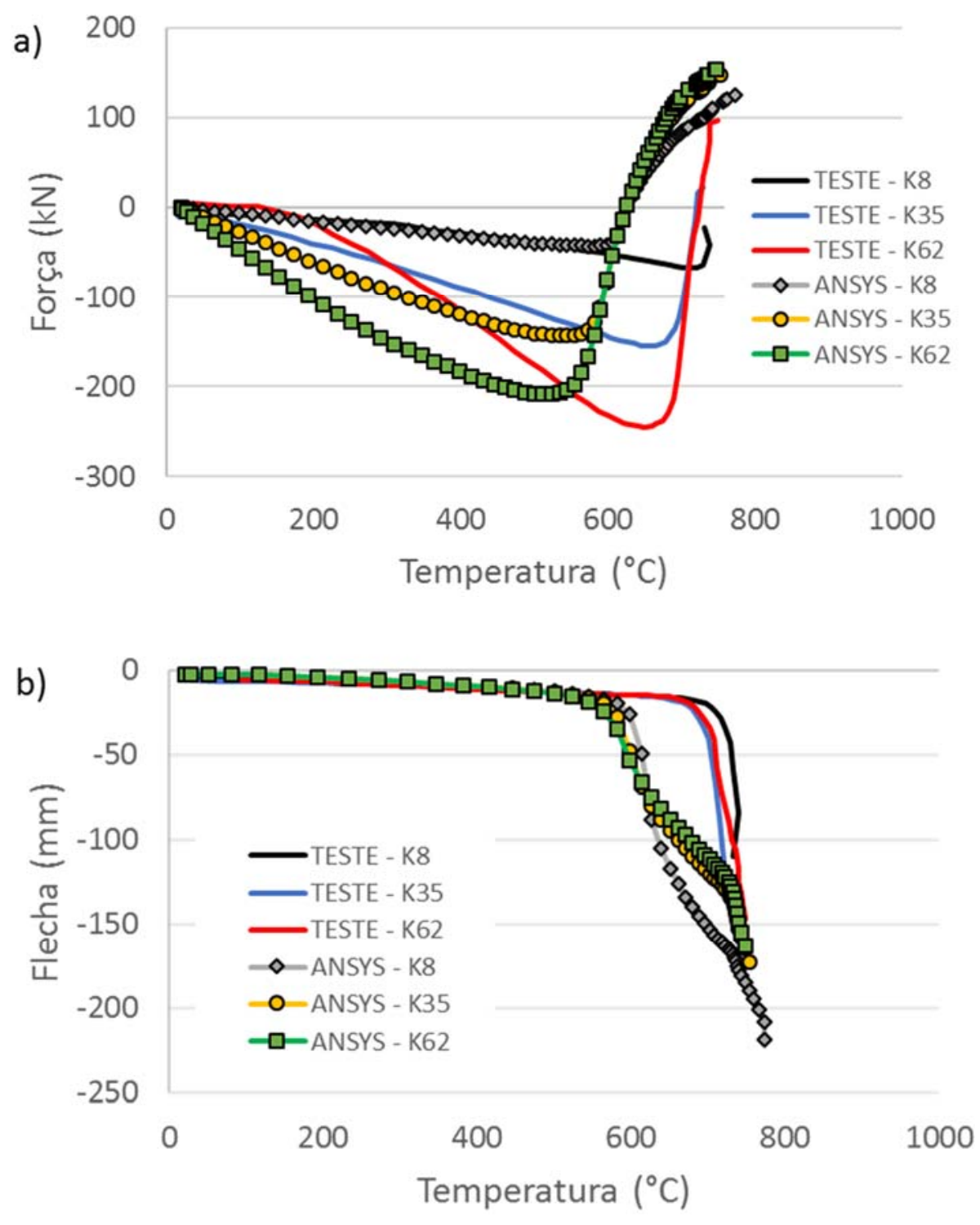

Figura 4.3 - Comparação entre os resultados experimental e numérico 
A Figura 4.4 mostra a deformada da viga no modelo numérico proposto e, comparandoa a Figura 2.3 do modelo experimental, observa-se que o comportamento da estrutura em ambos os modelos foi similar, apresentando instabilidade local na mesa inferior nas proximidades do apoio.

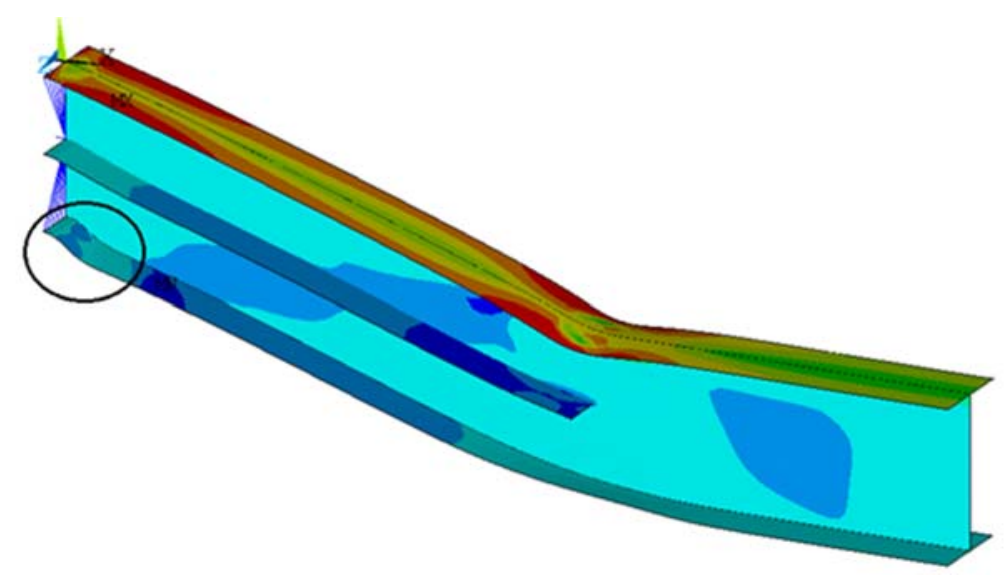

Figura 4.4 - Deformada da viga obtida após a análise numérica

\section{Conclusão}

Neste artigo foi simulado um ensaio de uma viga sem revestimento contra fogo, submetida a duas forças concentradas, com restrições axiais e rotacionais em situação de incêndio. A comparação entre os resultados experimentais e numéricos mostrou que, para a restrição axial de $8 \mathrm{kN} / \mathrm{mm}$, as curvas força-temperatura de ambos os resultados seguiram muito próximas até aproximadamente $600^{\circ} \mathrm{C}$. A inversão do esforço ocorreu pouco depois na análise numérica e o mesmo não foi observado no experimento, visto que o forno foi desligado a fim de se evitar danos provocados pelas grandes deformações. Quanto à restrição axial de $35 \mathrm{kN} / \mathrm{mm}$, as curvas força-temperatura seguiram próximas (entre $50^{\circ} \mathrm{Ce} 100^{\circ} \mathrm{C}$ ) até aproximadamente $600^{\circ} \mathrm{C}$, para em seguida a força no experimento aumentar até aproximadamente $650{ }^{\circ} \mathrm{C}$. De todas as comparações, a restrição axial de $62 \mathrm{kN} / \mathrm{mm}$ foi a que menos se aproximou. Apesar disso, com a mesma tendência, a inversão das curvas aconteceu a cerca de $500^{\circ} \mathrm{C}$ para a numérica e pouco mais de $600{ }^{\circ} \mathrm{C}$ para a experimental. Sobre as curvas flechatemperatura, notou-se que todas seguiram próximas até aproximadamente $600{ }^{\circ} \mathrm{C}$ para 
depois seguirem até o colapso. Em vista da falta de todas as informações experimentais, os resultados foram considerados satisfatórios. O modelo validado será usado no desenvolvimento de futuras pesquisas relacionadas ao tema.

\section{Agradecimentos}

Agradece-se ao CNPq - Conselho Nacional de Desenvolvimento Científico e Tecnológico, à CAPES - Coordenação de Aperfeiçoamento de Pessoal de Nível Superior e ao PPGECUFES - Programa de Pós-Graduação em Engenharia Civil da Universidade Federal do Espírito Santo.

\section{Referências}

ASSOCIAÇÃO BRASILEIRA DE NORMAS TÉCNICAS. NBR 14323:2013 Projeto de estruturas de aço e de estruturas mistas de aço e concreto de edifícios em situação de incêndio. Rio de Janeiro, 2013.

DORR, J.B. Modelos numéricos de pilares de aço em situação de incêndio considerando a influência da restrição axial. Dissertação de Mestrado. Escola de Engenharia de São Carlos, Universidade de São Paulo, 2010.

DWAIKAT M.M.S; KODUR V.K.R. A performance based methodology for fire design of restrained steel beams. Journal of Constructional Steel Research, v.67, 510-524, 2011.

EUROPEAN COMMITTEE FOR STANDARDIZATION. EN 1993 1-1: Eurocode 3 - Design of steel structures. Part 1-1: General rules and rules for buildings. Brussels, 2005.

HANUS, F. Calculation of internal forces in axially and rotationally restrained beams under natural fire. Dissertação de Mestrado. Université de Liège, 2008.

INTERNATIONAL ORGANIZATION FOR STANDARDIZATION. Fire resistance tests Elements of building construction. ISO 834, 1999.

KIMURA, E.F.A. Análise termo-estrutural de pilares de aço em situação de incêndio. Dissertação de Mestrado. Escola de Engenharia de São Carlos, Universidade de São Paulo, 2009.

KUCZ, M.; RZESZUT, K.; LUKASZ, P.; MALENDOWSKI, M. Influence of Boundary Conditions on the Thermal Response of Selected Steel Members. Procedia Engineering 57:977-985, (2013). 
LIU T.C.H; FAHAD M.K; DAVIES J.M. Experimental investigation of behaviour of axially restrained steel beams in fire. Journal of Constructional Steel Research. v.58, 1211-30, 2002.

LI G-Q; GUO S-X. Experiment on restrained steel beams subjected to heating and cooling. Journal of Constructional Steel Research. v.64, 268-74, 2008.

LI G.Q.; WANG, P.J.; JIANG, S.C. Non-linear finite element analysis of axially restrained steel beams at elevated temperatures in fire. Journal of Constructional Steel Research v.63, 1175-83, 2007.

MOSS, P.J.; BUCHANAN, A.H.; SEPUTRO, J.; WASTNEY, C.; WELSH, R. Effect of support conditions on the fire behavior of steel and composite beams. Fire and Materials 28:159-175, (2004).

MOURÃO, H.R. Sobre o comportamento de vigas de aço com flambagens impedidas, em situação de incêndio. Dissertação de Mestrado. Escola Politécnica da Universidade de São Paulo, 2004.

REGOBELLO, R. Análise numérica de seções transversais e de elementos estruturais de aço e mistos de aço e concreto em situação de incêndio. Dissertação de Mestrado. Escola de Engenharia de São Carlos, Universidade de São Paulo, 2007.

SILVA, V.P. Estruturas de aço em situação de incêndio. Tese de Doutorado. Departamento de Estruturas e Fundações da Escola Politécnica da Universidade de São Paulo, 1997.

TAN, K.H.; HUANG, Z.F. Structural responses of axially restrained steel beams with semirigid moment connection in fire. Journal of Structural Engineering. v.131(4), 54151, 2005.

YIN, Y.Z.; WANG, Y.C. A numerical study of large deflection behaviour of restrained steel beams at elevated temperatures. Journal of Constructional Steel Research. v.60, 1029-1047, 2004. 